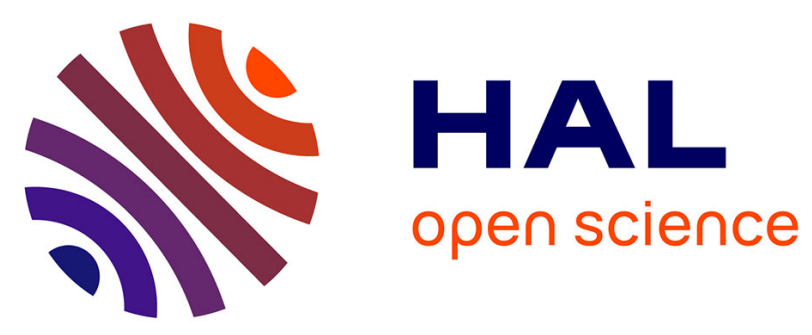

\title{
The integrated production-inventory-routing problem in the context of reverse logistics: The case of collecting and remanufacturing of EOL products
}

\author{
Zakaria Chekoubi, Wajdi Trabelsi, Nathalie Sauer
}

\section{- To cite this version:}

Zakaria Chekoubi, Wajdi Trabelsi, Nathalie Sauer. The integrated production-inventory-routing problem in the context of reverse logistics: The case of collecting and remanufacturing of EOL products. 4th International Conference on Optimization and Applications (ICOA), Apr 2018, Mohammedia, Morocco. 10.1109/ICOA.2018.8370563 . hal-01873513

\section{HAL Id: hal-01873513 \\ https://hal.science/hal-01873513}

Submitted on 19 Sep 2018

HAL is a multi-disciplinary open access archive for the deposit and dissemination of scientific research documents, whether they are published or not. The documents may come from teaching and research institutions in France or abroad, or from public or private research centers.
L'archive ouverte pluridisciplinaire HAL, est destinée au dépôt et à la diffusion de documents scientifiques de niveau recherche, publiés ou non, émanant des établissements d'enseignement et de recherche français ou étrangers, des laboratoires publics ou privés. 
See discussions, stats, and author profiles for this publication at: https://www.researchgate.net/publication/324865644

\section{The Integrated Production-Inventory-Routing problem in the context of Reverse Logistics: the case of collecting and remanufacturing of EOL products}

Conference Paper · April 2018

DOI: 10.1109/ICOA.2018.8370563

CITATIONS

0

3 authors, including:

Chekoubi Zakaria

University of Lorraine

1 PUBLICATION OCITATIONS

SEE PROFILE

Some of the authors of this publication are also working on these related projects:

VRPSPD with heterogeneous fleet View project
READS

54

Wajdi Trabelsi

ICN Business School

13 PUBlications 26 Citations

SEE PROFILE 


\section{The Integrated Production-Inventory-Routing problem in the context of Reverse Logistics: the case of collecting and remanufacturing of EOL products}

\author{
Zakaria CHEKOUBI ${ }^{1,2}$ \\ ${ }^{1}$ LGIPM/Université de Lorraine \\ ${ }^{2}$ LIDRA/Universiapolis \\ Metz, France \\ zakaria.chekoubi@univ-lorraine.fr
}

\author{
Wajdi TRABELSI \\ LGIPM \\ ICN Business School \\ Metz, France \\ wajdi.trabelsi@icn-artem.com
}

\author{
Nathalie SAUER \\ LGIPM \\ Université de Lorraine \\ Metz, France \\ nathalie.sauer@univ-lorraine.fr
}

\begin{abstract}
Production-planning, inventory control with returns management, and vehicle routing are critical and highly related problems in the design of closed-loop supply chain networks. In this paper, we address an extension of the Integrated ProductionInventory-Routing Problem (IPIRP) since we consider recovery and remanufacturing of End-Of-Life (EOL) products as a sustainable aspect. A mathematical programming formulation is proposed for the considered problem. The objective is to determine both the optimal amounts of goods (lot-sizes) to be manufactured, remanufactured and stored while meeting customers' requests (deliveries and pick-ups) with a minimum total cost due to the integrated operations considered. The originality of our study lies in the fact of jointly treating the capacited dynamic lot-sizing with remanufacturing problem and the vehicle routing problem with simultaneous pick-up and delivery. Some numerical examples to illustrate the relevance of our proposed model are given.
\end{abstract}

Keywords-Integrated Production-Inventory-Routing Problem, Lot-sizing, Remanufacturing, Inventory control, VRP with Simultaneous Pick-up and Delivery, Reverse logistics, Closed-Loop Supply Chain, Mixed Integer Linear Programming.

\section{INTRODUCTION}

Managing reverse flow within a close-loop supply chain is considered as a business opportunity for many companies. Today, many firms have initiated efforts to incorporate the concept of reverse logistics in their regular production, inventory and distribution decision systems for several reasons such as the increasing concern for environment, restrictions of applicable government regulations and laws on recycled products and waste disposal, the growing energy consumptions, and the stiff competition between the firms. The integration of these three decisions on the context of reverse supply chains offers tremendous cost savaging opportunities to firms. Moreover, integrating production-inventory-distribution decisions into a single problem is almost indispensable and relevant for some type of goods in particular perishable or timesensitive goods. The Integrated Production-Inventory-Routing Problem (IPIRP) is considered as a new OR field which aims to jointly optimize these three decision levels. It can be described as follows: a plant produces and stocks single or multiple products and distributes them to multiple customers (even by direct shipment or by a special customer sequence) over a multi- period time horizon by jointly considering all the three decisions. Most existing studies on this problem consider the strategic or tactical level [1]. At the strategic level, decisions about facility location and plant capacity are taken [2]. The tactical level deals with production lot sizes, inventory levels, delivery quantities and routing paths. A recent review of integrated tactical level problems can be found in [3]. The operational level deals with the integration of machine scheduling and distribution decisions. A recent review on the integrated operational level can be found in [2]. Therefore, the IPIRP can be seen as an integration of three-level lot-sizing, inventory control and routing problems, each of them is quite difficult to solve. Because the IPIRP is NP-hard, there are only few exact algorithms available in the literature ([1], [4] and [5]) and these algorithms can only solve small-scale instances. Moreover, many heuristics have been proposed for several variants of the IPIRP ([6], [7], [8]). For a recent review on the IPIRP, readers can refer to [9], [10] and [11]. Furthermore, studying the IPIRP in the context of reverse logistics makes it more challenging issue especially at the tactical level. Our study considers this relevant application area by considering an extension of the IPIRP in which we jointly consider the wellknown Capacited Dynamic Lot-Sizing with Remanufacturing (CDLSR), at production-inventory decision level, and Vehicle Routing Problem with Simultaneous Pickup and Delivery, at routing decision level. We called resulting integrated problem as CDLSR-VRPSPD problem. The first part of the integrated CDLSR-VRPSPD problem deals with the single lot-sizing problem with remanufacturing and inventory control system. The concept of remanufacturing consists on transforming endof-life returned products (reverse flows) into usable products through refurbishment, repair or upgrading. Today many firms voluntary collect end-of-life products to recover residual value and might even design their products to maximize this value [12]. The remanufactured products have usually the same quality as the new products (serviceables) and are sold for the same price, but, they are almost loss costly. Also, these products can also be used to fulfil customers' requests. This is why remanufacturing plays, nowadays, a crucial role in the overall production, inventory and distribution systems. Furthermore, one of the significant problems that arises in such kind of production systems is the dynamic lot sizing problem. In [13], 
the authors addressed the dynamic lot sizing problem for the first time. The so-called Wagner-Whitin problem assumes a finite planning horizon; demand is given for each interval and may vary over time; capacity constraints are not considered and a single item of a single-level product is produced. The problem is to determine the number of items to be produced in each time period in order to satisfy the demands while minimizing the total production, setup and inventory costs. Moreover, in the recent literature, there has been an increasing interest in the study of lot-sizing problems with remanufacturing due to their large applicability in reverse logistics. Two recent reviews on the modelling of lot-sizing and reverse logistics inventory systems are given by [14] and [15]. Mainly, the single-item dynamic lotsizing problem with remanufacturing (SDLSR) has attracted the attention of several authors during the last years. One of the most important extensions of the SDLSR problem, is the Capacited Dynamic Lot-Sizing with Remanufacturing (CDLSR) problem in which limited production capacity is considered. Several extensions of the CDLSR problem can be found in [16] and [17]. Recent, works on heuristics approaches can be found on [18], [19] and [20]. For recent review of mixed integer programming techniques, readers can refer to [21] and [22].

The second part of the integrated CDLSR-VRPSPD problem considers the VRP with simultaneous pickup and delivery which is one of the most known variants of the classical VRP. In VRPSPD, the vehicles (homogeneous or heterogenous fleet) are not only required to deliver goods to customer, but also pickup goods at customer locations [23]. A general assumption in VRPSPD is that all delivered goods must be originated from the depot, all pickup goods must be transported back to the depot. Delivery and pickup goods must be met simultaneously when each customer is visited only once by a vehicle and unloading is carried out before loading at the customers without violating vehicle capacity constraints [24]. Also, the VRPSPD is very used and more relevant in reverse logistics application area. Thus, after VRPSPD has been introduced by [25], the research on this problem has been mainly focused on heuristic and metaheuristic approaches ([26], [27], [28], and [29]). An exact method, based on branch and price approach, has been developed by [30]. Interested readers can refer to [31] and [32] for further investigated VRPSPD extensions and reviews.

Despite the increasing of studies describing a variety of variants and models for the IPIRP, few studies consider this problem in the context of reverse logistics. Moreover, to our best knowledge, there is no study considering jointly the CDLSR and VRPSPD problems. In this paper, a particular closed-loop supply chain network integrating production planning, inventory control and distribution decisions is considered.

The main scientific contributions of our study are summarized as follows. (a) It provides a modelling approach for the integrated production-inventory-routing problem with returns management. (b) Our study offers a novel MILP formulation in which we conjointly optimize the Capacited Dynamic Lot-Sizing with Remanufacturing and the VRP with Simultaneous Pickup and Delivery. Finally, (c) our study provides managerial insights in the trade-offs among the integrated operational decisions.
The remainder of the paper is organized as follows. In Section 2, we provide a brief description of the considered problem as well as the assumptions adopted to develop our mathematical model. In section 3, we formally define the problem and present a MILP formulation. Computational experiments and the obtained results are described in section 4. Finally, we conclude our paper with some perspectives for future research work.

\section{PROBLEM DESCRIPTION}

This section provides a formal description of the CDLSRVRPSPD problem and then presents the assumptions we considered to develop the MILP formulation model of the considered problem.

Let $G=(N, A)$ be a complete directed graph network with $N=\{0\} \cup\{1,2, \ldots, n\}=\{0\} \cup N_{C}$ the set of nodes and $A=$ $\{(i, j): i, j \in N, i \neq j\}$ the set of arcs. The node $\{0\}$ represents the central depot and the others represent the costumers. Each $\operatorname{arc}(i, j) \in A$ has a non-negative symmetric routing $\operatorname{cost} c_{i j}$ that represents the cost for reaching node $j$ from node $i$ and satisfying triangular inequality (i.e., $c_{i j}+c_{j k} \geq c_{i k}$ ). Each customer $i \in N_{C}$ has a periodic demand including delivery $d_{i t}$ and pickup $p_{i t}$ (we assume $\left.d_{0 t}=p_{0 t}=0 \forall t \in T\right)$. We consider a single vehicle with capacity $Q$ (we assume that $Q>$ $\left.\max _{t \in T}\left\{\sum_{i \in N_{C}} d_{i t} ; \sum_{i \in N_{C}} p_{i t}\right\}\right)$ and a fixed cost $F_{C}$. At the central depot are located two production systems, respectively, for manufacturing and remanufacturing of new products (serviceables) and return-products. The production strategy of both systems is based on the economic lot-sizing with capacity of a single product for which the demand requirements of each period over the finite planning horizon must be satisfied either by manufacturing new products or by remanufacturing end-oflife products returned to the returns inventory. The studied closed-loop supply chain can be modelled as shown in Fig.1.

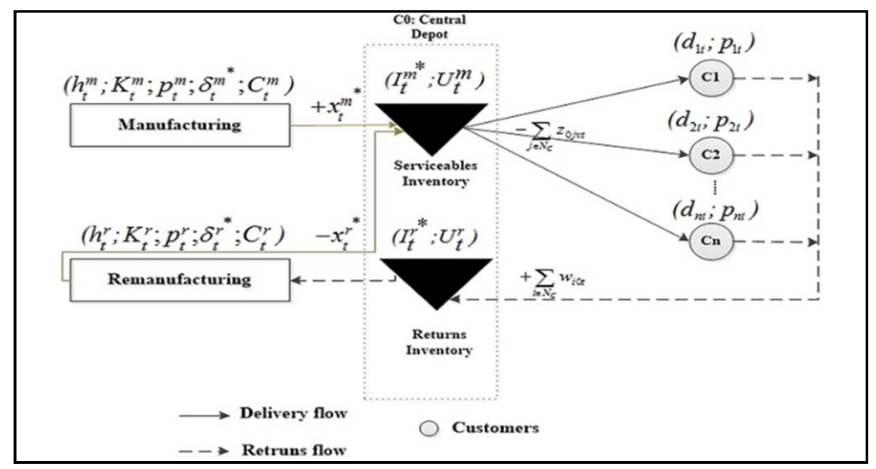

Fig. 1: CONSIDERED CLOSED-LoOP SuPPLy ChaIN SYSTEM

The objective of the CDLSR-VRSPD problem is to determine the optimal integrated planning that minimizes the sum of setup, manufacturing, remanufacturing, holding and transportation costs by determining the optimal amounts of goods to be manufactured, remanufactured, stored and to be distributed through optimal routes. The following assumptions are considered: 
Production level: we consider the mono-item dynamic lot sizing policy for both manufacturing and remanufacturing production systems. Each production line has a production capacity should not to be exceeded in each period. Furthermore, each production system has its own set-up cost. In addition, a unitary production cost occurs for manufacturing (resp., remanufacturing) a new product (resp., returned product) in each period. We also assume that manufacturing and remanufacturing lead times are zero. Moreover, we consider that all demands (delivery and pickup) are known for all periods of planning horizon. Also, the remanufactured products will be of the same quality as new products and backlogging is not allowed.

Inventory level: We assume that the initial stocks of serviceables and returns are both predefined (zero initial stocks conditions) and that there us a positive demand in the first period. Moreover, we assume that new manufactured (resp., remanufactured) products are stored in the serviceables (resp., returns inventory) without exceeding its periodic capacity. We consider also that demand is meet either from newly manufactured products or from the remanufactured returns or both. We also assume that each inventory has its own periodic holding cost.

Vehicle routing level: we assume that the vehicle route starts and ends at the central depot, and every customer is visited at most once by the vehicle in each time period and each customer with zero requests should not be visited $\left(d_{i t}>0\right.$ and $\left.p_{i t} \leq Q\right)$. Also, the vehicle should perform pickup and delivery simultaneously. Furthermore, the vehicle total load should not exceed its capacity.

\section{MATHEMATICAL FORMULATION}

In this section, we provide a mixed integer linear program (MILP) formulation for the CDLSR-VRPSPD problem which we used to solve some small instances.

\section{A. Parameters}

To formulate the problem, following parameters are used:

$N$ : set of all nodes (node 0 represents production facilities and central depot)

$N_{C}=N \backslash\{0\}$ : set of nodes (customers) without node 0

$T$ : number of time periods (horizon planning), $t \in\{1, \ldots, T\}$

$d_{i t}$ : delivery demand of customer $i \in N_{\mathrm{C}}$ at period $t$

$p_{i t}$ : pick-up demand of customer $i \in N_{\mathrm{C}}$ at period $t$

$h_{t}^{m}$ : unitary holding cost of one serviceable product at period $t$

$h_{t}^{r}$ : unitary holding cost of one return-product at period $t$

$K_{t}^{m}$ : set-up cost for manufacturing at period $t$

$K_{t}^{r}$ : set-up cost for remanufacturing at period $t$

$p_{t}^{m}$ : unitary production cost for manufacturing at period $t$

$p_{t}^{r}$ : unitary production cost for remanufacturing at period $t$

$C_{t}^{m}$ : maximal production capacity of manufacturing system at period $t$

$C_{t}^{r}$ : maximal production capacity of remanufacturing system at $t$

$U_{t}^{m}$ : maximum storage capacity of serviceable products at $t$
$U_{t}^{r}$ : maximum storage capacity of return-products at $t$

$Q$ : vehicle capacity;

$F_{C}$ : fixed vehicle cost;

$c_{i j}$ : transportation cost between node $i$ and node $j$ (assume $c_{i j}=$ $c_{j i}$ and $\left.c_{i i}=0 \forall(i, j) \in A\right)$

\section{B. Variables}

Used variables in this model are as follows:

$x_{t}^{m}$ : number of products manufactured in period $t$

$x_{t}^{r}$ : number of products remanufactured in period $t$

$I_{t}^{m}$ : inventory level of serviceables at the end of period $t$

$I_{t}^{r}$ : inventory level of returns at the end of period $t$

$z_{i j t}$ : amount of delivery goods on board on $\operatorname{arc} \forall(i, j) \in A$ at $t$

$w_{i j t}$ : amount of pickup goods on board on arc $\forall(i, j) \in A$ at $t$

$\delta_{t}^{m}=\{1$ if new products are manufactured in period $t$ (e.g., if $\left.x_{t}^{m}>0\right)$; 0otherwise $\}$

$\delta_{t}^{r}=\{1$ if new products are remanufactured in period $t$ (e.g., if $x_{t}^{r}>0 ; 0$ otherwise $\}$

$y_{i j t}=\{1$ if the vehicle travels directly from customer $i$ to customer $j$; 0 otherwise $\}$

\section{Model}

With the above introduced parameters and variables, we present the mathematical model for solving the considered problem. The integrated planning model is as follows:

$$
\begin{aligned}
\min z=\sum_{t=1}^{T}\left(K_{t}^{m}\right. & \cdot \delta_{t}^{m}+p_{t}^{m} \cdot x_{t}^{m}+h_{t}^{m} \cdot I_{t}^{m}+K_{t}^{r} \cdot \delta_{t}^{r} \\
& +p_{t}^{r} \cdot x_{t}^{r}+h_{t}^{r} \cdot I_{t}^{r}+\sum_{j \in \mathrm{N}_{C}} F c \cdot y_{0 j t} \\
& \left.+\sum_{i \in \mathrm{N}} \sum_{\substack{j \in \mathrm{N} \\
\mathrm{j} \neq \mathrm{i}}} c_{i j} \cdot y_{i j t}\right)
\end{aligned}
$$

$$
\begin{aligned}
& I_{t}^{m}=I_{t-1}^{m}+x_{t}^{m}+x_{t}^{r}-\sum_{j \in \mathrm{N}_{C}} z_{0 j t} \quad \forall \mathrm{t} \in \mathrm{T} \\
& I_{t}^{r}=I_{t-1}^{r}-x_{t}^{r}+\sum_{i \in \mathrm{N}_{C}} w_{i 0 t} \quad \forall \mathrm{t} \in \mathrm{T} \\
& I_{0}^{m}=I_{\text {init }}^{m} ; I_{0}^{r}=I_{\text {init }}^{r} \\
& 0 \leq I_{t}^{m} \leq U_{t}^{m} \\
& \forall \mathrm{t} \in \mathrm{T} \\
& 0 \leq I_{t}^{r} \leq U_{t}^{r} \\
& \forall \mathrm{t} \in \mathrm{T} \\
& x_{t}^{m} \leq \min \left\{\sum_{i \in \mathrm{N}_{C}} \sum_{l=t}^{T} d_{i l} ; C_{t}^{m}\right\} . \delta_{t}^{m} \quad \forall \mathrm{t} \in \mathrm{T} \\
& x_{t}^{r} \leq \min \left\{\sum_{i \in \mathrm{N}_{C}} \sum_{l=t}^{T} d_{i l} ; \sum_{i \in \mathrm{N}_{C}} \sum_{l=t}^{T} p_{i l} ; C_{t}^{r}\right\} . \delta_{t}^{r} \\
& \sum_{\substack{\mathrm{i} \in \mathrm{N} \neq \mathrm{j} \\
\mathrm{ijt}}} \mathrm{y}_{\mathrm{ij}} \\
& \forall \mathrm{t} \in \mathrm{T} \\
& \sum_{\substack{j \in \mathrm{N} \\
\mathrm{j} \neq \mathrm{i}}} y_{i j t}-\sum_{\substack{j \in \mathrm{N} \\
\mathrm{j} \neq \mathrm{i}}} y_{j i t}=0 \\
& \forall \mathrm{j} \in \mathrm{N}_{\mathrm{C}} ; \forall \mathrm{t} \in \mathrm{T} \\
& \forall \mathrm{j} \in \mathrm{N} ; \quad \forall \mathrm{t} \in \mathrm{T} \\
& \sum_{j \in \mathrm{N}_{C}} y_{0 j t} \leq 1 \\
& \forall \mathrm{t} \in \mathrm{T}
\end{aligned}
$$




$$
\begin{array}{lr}
y_{i j t}+y_{j i t} \leq 1 & (\forall \mathrm{i}, \mathrm{j} \in \mathrm{N}: \mathrm{i} \neq \mathrm{j}) ; \forall \mathrm{t} \in \mathrm{T} \\
\sum_{\substack{i \in \mathrm{N} \\
i \neq \mathrm{j}}} z_{i j t}-\sum_{\substack{i \in \mathrm{N} \\
\mathrm{i} \neq \mathrm{j}}} z_{j i t}=d_{j t} & \forall \mathrm{j} \in \mathrm{N}_{\mathrm{C}} ; \forall \mathrm{t} \in \mathrm{T} \\
\sum_{\substack{i \in \mathrm{N} \\
\mathrm{i} \neq \mathrm{j}}} w_{j i t}-\sum_{\substack{i \in \mathrm{N} \\
\mathrm{i} \neq \mathrm{j}}} w_{i j t}=p_{j t} & \forall \mathrm{j} \in \mathrm{N}_{\mathrm{C}} ; \forall \mathrm{t} \in \mathrm{T} \\
x_{t}^{r} \leq I_{t-1}^{r} & \forall \mathrm{t} \in \mathrm{T} \\
\sum_{i \in \mathrm{N}_{C}} w_{i 0 t}=\sum_{i \in \mathrm{N}_{C}} p_{i t} & \forall \mathrm{t} \in \mathrm{T} \\
\sum_{j \in \mathrm{N}_{C}} w_{0 j t}=0 & \forall \mathrm{t} \in \mathrm{T} \\
\sum_{i \in \mathrm{N}_{C}} z_{0 i t}=\sum_{i \in \mathrm{N}_{C}} d_{i t} & \forall \mathrm{t} \in \mathrm{T} \\
\sum_{i \in \mathrm{N}_{C}} z_{i 0 t}=0 & \forall \mathrm{t} \in \mathrm{T} \\
z_{i j t}+w_{i j t} \leq Q \cdot y_{i j t} & \forall(\mathrm{i}, \mathrm{j}: \mathrm{i} \neq \mathrm{j}) \in \mathrm{N} ; \forall \mathrm{t} \in \mathrm{T} \\
z_{i j t} \geq d_{j t} \cdot y_{i j t} & \forall(\mathrm{i}, \mathrm{j}: \mathrm{i} \neq \mathrm{j}) \in \mathrm{N} ; \forall \mathrm{t} \in \mathrm{T} \\
z_{i j t} \leq\left(Q-d_{i t}\right) \cdot y_{i j t} & \forall(\mathrm{i}, \mathrm{j}: \mathrm{i} \neq \mathrm{j}) \in \mathrm{N} ; \forall \mathrm{t} \in \mathrm{T} \\
w_{i j t} \geq p_{i t} \cdot y_{i j t} & \forall(\mathrm{i}, \mathrm{j}: \mathrm{i} \neq \mathrm{j}) \in \mathrm{N} ; \forall \mathrm{t} \in \mathrm{T} \\
w_{i j t} \leq\left(Q-p_{j t}\right) \cdot y_{i j t} & \forall(\mathrm{i}, \mathrm{j}: \mathrm{i} \neq \mathrm{j}) \in \mathrm{N} ; \forall \mathrm{t} \in \mathrm{T} \\
y_{i j t} \in\{0,1\} & \forall(\mathrm{i}, \mathrm{j}: \mathrm{i} \neq \mathrm{j}) \in \mathrm{N} ; \forall \mathrm{t} \in \mathrm{T} \\
\delta_{t}^{m} \in\{0,1\} ; \delta_{t}^{r} \in\{0,1\} & \forall \mathrm{t} \in \mathrm{T} \\
x_{t}^{m}, x_{t}^{r}, I_{t}^{m}, I_{t}^{r}, z_{i j t}, w_{i j t} \in \mathbb{Z}^{+} & \forall(\mathrm{i}, \mathrm{j}: \mathrm{i} \neq \mathrm{j}) \in \mathrm{N} ; \forall \mathrm{t} \in \mathrm{T}
\end{array}
$$

The objective function (1) minimizes the sum of setup, manufacturing, remanufacturing, holding and transportation costs. Constraints (2)-(4) are flow balance equations and initial inventories conditions for serviceable and return products respectively. Constraints (5)-(6) define, respectively, the maximum storage capacity of serviceable and return products not to be exceeded during each period. Constraints (7)-(8) ensure that the quantities of manufactured (resp. remanufactured) products do not exceed manufacturing definite limits. Constraints (9)-(12) are vehicle routing constraints. Constraint (9) ensures that the vehicle visits at most a customer per period. Constraint (10) represents the flow conservation, while the constraint (11) guarantees that one vehicle must be used. Constraints (12) ensures that any feasible route does not

\begin{tabular}{|c|c|}
\hline Time horizon $(T)$ & Possible values $\{3,6,9\}$ \\
\hline Number of customers $\left(N_{C}\right)$ & Possible values $\{5,10,15,20\}$ \\
\hline $\begin{array}{l}\text { Manufactirung production } \\
\text { line capacity }\left(C_{t}^{m}\right)\end{array}$ & Calculated as: $2 \cdot \sum_{i \in N_{C}} \sum_{t \in T} \frac{d_{i t}}{T}$ \\
\hline $\begin{array}{c}\text { Remanufactirung } \\
\text { production line capacity } \\
\left(C_{t}^{r}\right)\end{array}$ & Calculated as: $2 \cdot \sum_{i \in N_{C}} \sum_{t \in T} \frac{p_{i t}}{T}$ \\
\hline Vehicle capacity $(Q)$ & $\begin{array}{c}\text { Calculated as: } \\
Q>\max _{t \in T}\left\{\sum_{i \in N_{C}} d_{i t} ; \sum_{i \in N_{C}} p_{i t}\right\}\end{array}$ \\
\hline $\begin{array}{c}\text { Customers delivery } \\
\text { demand in each period } \\
\left(d_{i t}\right)\end{array}$ & Uniform distribution $\mathrm{U}(20 ; 60)$. \\
\hline $\begin{array}{l}\text { Customers pickup demand } \\
\text { in each period }\left(p_{i t}\right)\end{array}$ & Uniform distribution $\mathrm{U}(5 ; 20)$. \\
\hline $\begin{array}{l}\text { Maximum storage capacity } \\
\text { of serviceable inventory in } \\
\text { each period }\left(U_{t}^{m}\right)\end{array}$ & Calculated as: $2 \cdot \sum_{i \in N_{C}} \sum_{t \in T} \frac{d_{i t}}{T} \cdot\left|N_{C}\right|$ \\
\hline $\begin{array}{c}\text { Maximum strorage } \\
\text { capacity of retruns } \\
\text { inventory in each perdion } \\
\left(U_{t}^{r}\right)\end{array}$ & Calculated as: $2 \cdot \sum_{i \in N_{C}} \sum_{t \in T} \frac{p_{i t}}{T} \cdot\left|N_{C}\right|$ \\
\hline $\begin{array}{l}\text { Manufacturing setup cost } \\
\text { at each period }\left(K_{t}^{m}\right)\end{array}$ & Possible value 500 \\
\hline $\begin{array}{l}\text { Remanufacturing setup } \\
\text { cost at each period }\left(K_{t}^{r}\right)\end{array}$ & Possible value 500 \\
\hline $\begin{array}{c}\text { Unitary production cost for } \\
\text { manufacturing in each } \\
\text { period }\left(p_{t}^{m}\right)\end{array}$ & Possible value 10 \\
\hline $\begin{array}{l}\text { Unitary production cost for } \\
\text { remanufacturing in each } \\
\text { period }\left(p_{t}^{r}\right)\end{array}$ & Possible value 2 \\
\hline $\begin{array}{l}\text { Unitary holding cost for } \\
\text { manufactured product }\left(h_{t}^{m}\right)\end{array}$ & Possible value 1 \\
\hline $\begin{array}{l}\text { Unitary holding cost of } \\
\text { return-product }\left(h_{t}^{r}\right)\end{array}$ & Possible value 0.8 \\
\hline Vehicle fixed cost $(F c)$ & 500 \\
\hline & Calculated as: \\
\hline Transportation cost $\left(c_{i j}\right)$ & {$\left[\sqrt{\left(x_{i}-x_{j}\right)^{2}+\left(y_{i}-y_{j}\right)^{2}+0.5}\right]$} \\
\hline $\begin{array}{l}\text { Initial level of serviceable } \\
\text { inventory }\left(I_{\text {init }}^{m}\right)\end{array}$ & 0 \\
\hline $\begin{array}{l}\text { Initial level of returns } \\
\text { inventory }\left(I_{\text {init }}^{r}\right)\end{array}$ & 0 \\
\hline
\end{tabular}
contain sub-tours with only two customers. Constraint (13)-(14) guarantee that the delivery and pickup demands at customer $j$ are satisfied. Constraint (15) ensures that the quantity of remanufactured products at the actual period was held in the returns inventory in the previous period. This constraint guarantees the policy 'remanufacturing after collecting'. Constraint (16) ensures that the total pickup load on the last arcs is equal to the total pickup demand, while constraint (17) guaranties that the load on the first arcs is zero. Similarly, constraints (18) and (19) determine the delivery loads on the first and the last arcs. Constraint (20) guaranties that the total load on the vehicle does not exceed its capacity. Constraints (21)-(24) are called as bounding constraints and restrict the upper and lower bounds of the quantities to be delivered and to be collected on all arcs. Finally, constraints (25)-(27) define the nature of the decision variables considered.

\section{COMPUTATIONAL RESUlTS}

\section{A. Instance generation}

We implemented our model and tested all the generated instances using the commercial solver IBM ILOG CPLEX 12.7 on a PC with CPU Core i5 $(2.40 \mathrm{GHz})$ and 4 GB RAM. Moreover, we used the default configuration of the considered solver for all performed tests. The program execution is stopped even when the optimum is found or after a time limit of $3600 \mathrm{~s}$.

The data sets were generated based on some adapted data sets from the literature of lot-sizing with remanufacturing problems and those from the integrated production routing problems in particular research works of [20] and [33]. All numerical instances were generated according to the parameters values shown in Table 1.

TABLE 1: GENERATION OF INSTANCES

The numerical tests were done on a set of problems that were generated by varying the number of time periods $(|T|)$, the delivery demands $\left(d_{i t}\right)$ and the pickup demands $\left(p_{i t}\right)$. We obtain 
a total of $10 * 3=30$ problems (combinations), and for each problem five instances are randomly generated by drawing the delivery $\left(d_{i t}\right)$ and the pickup demands $\left(p_{i t}\right)$ from uniform distribution. Also, we change the travelling cost $\left(c_{i j}\right)$ from one problem to another one by redrawing new coordinates and calculating the new $c_{i j}$ cost matrix for the new problem. A total of $10 * 3 * 5=150$ instances were generated and tested by the MILP formulation presented in the previous section.

\section{B. Numerical results and analysis:}

To test the efficiency and the limits of our MILP formulation, we analysed the obtained results from CPLEX solver in term of the average CPU time in regards to problems sizes. The summary of computational results is given in Table 2 . In this table columns Ave. Tot. Cost, Ave. CPU (s) and \#OPT show the average CPU time in seconds, the average of the total cost and the number of instances solved to optimality, respectively.

TABLE 2: SUMMARY OF COMPUTATIONAL RESULTS $((*)$ SIGNIFICATES THAT THE AVE. CPU (S) WAS CALCULATED BASED ONLY ON THE SOLVED INSTANCES)

\begin{tabular}{|c|c|c|c|c|c|c|}
\hline Prob.\# & $\left|\mathbf{N}_{\mathbf{C}}\right|$ & $|\mathbf{T}|$ & \#Ins. & Ave. Tot. Cost & $\begin{array}{c}\text { Ave. } \\
\text { CPU (s) }\end{array}$ & \#OPT \\
\hline 1 & & 3 & 5 & 9644 & 0,148 & 5 \\
\hline 2 & 5 & 6 & 5 & 16681,8 & 0,432 & 5 \\
\hline 3 & & 9 & 5 & 25725,84 & 0,48 & 5 \\
\hline 4 & & 3 & 5 & 14418,08 & 0,964 & 5 \\
\hline 5 & 10 & 6 & 5 & 28002,96 & 3,688 & 5 \\
\hline 6 & & 9 & 5 & 42298,52 & 1,2 & 5 \\
\hline 7 & & 3 & 5 & 19789,6 & 2,274 & 5 \\
\hline 8 & 15 & 6 & 5 & 39248,36 & 4,62 & 5 \\
\hline 9 & & 9 & 5 & 57242,44 & 5,476 & 5 \\
\hline 10 & & 3 & 5 & 26300,84 & 10,3 & 5 \\
\hline 11 & 20 & 6 & 5 & 48405,92 & 21,16 & 5 \\
\hline 12 & & 9 & 5 & 70064,08 & 55,318 & 5 \\
\hline 13 & & 3 & 5 & 30230,76 & 17,272 & 5 \\
\hline 14 & 25 & 6 & 5 & 59657,52 & 111,63 & 5 \\
\hline 15 & & 9 & 5 & 87066,76 & 102,094 & 5 \\
\hline 16 & & 3 & 5 & 35803,6 & 60 & 5 \\
\hline 17 & 30 & 6 & 5 & 67476,2 & 160,242 & 5 \\
\hline 18 & & 9 & 5 & 100826,56 & 184,152 & 5 \\
\hline 19 & & 3 & 5 & 41216,56 & 136,256 & 5 \\
\hline 20 & 35 & 6 & 5 & 77410,4 & 297,349 & 5 \\
\hline 21 & & 9 & 5 & 114921,44 & 428,772 & 5 \\
\hline 22 & & 3 & 5 & 46145,4 & 376,342 & 5 \\
\hline 23 & 40 & 6 & 5 & 88316,2 & 379,292 & 5 \\
\hline 24 & & 9 & 5 & $129821,55^{(*)}$ & $>3600$ & 4 \\
\hline 25 & & 3 & 5 & 52040,6 & 299,566 & 5 \\
\hline 26 & 45 & 6 & 5 & $96612,15^{(*)}$ & $>3600$ & 4 \\
\hline 27 & & 9 & 5 & - & $>3600$ & $\mathbf{0}$ \\
\hline 28 & & 3 & 5 & 56447,92 & 551,968 & 5 \\
\hline 29 & 50 & 6 & 5 & $106717.2^{(*)}$ & $>3600$ & 1 \\
\hline 30 & & 9 & 5 & - & $>3600$ & $\mathbf{0}$ \\
\hline
\end{tabular}

Based on the computational results given in Table 2 and the graphic of Fig.2, it is easy to observe that the proposed MILP formulation is very sensitive to the number of periods $(|T|)$ and number of customers $\left(\left|N_{C}\right|\right)$. Indeed, as shown in Fig. 2, when the number of customers rises from 30 to 50 , the average CPU time shows a sharp increase for all possible time period values, especially, when $|T|=9$ and $\left|N_{C}\right| \geq 40$. We can also observe that Cplex has solved only 4 instances in the case of problem 26, and just 1 instance in the case of problem 29 out of 5 instances with an average CPU time that exceeded the one-hour time limit. The same fact can be observed for problems 27, 29 and 30 where Cplex was unable to solve no instance within the limit time of one hour.

These observations can be explained by the fact that the developed model induces a large number of decision variables and also by the fact that it considers the joint optimization of the capacited dynamic lot-sizing problem with remanufacturing and the vehicle routing problem with simultaneous pick-up and delivery problem each of them is NP-Hard.

FIG. 2: EFFECTS OF NUMBER OF TIME PERIODS $(|\boldsymbol{T}|)$ AND THE NUMBER OF CUSTOMERS $\left|\boldsymbol{N}_{\boldsymbol{C}}\right|$ ON THE AVERAGE CPU TIME

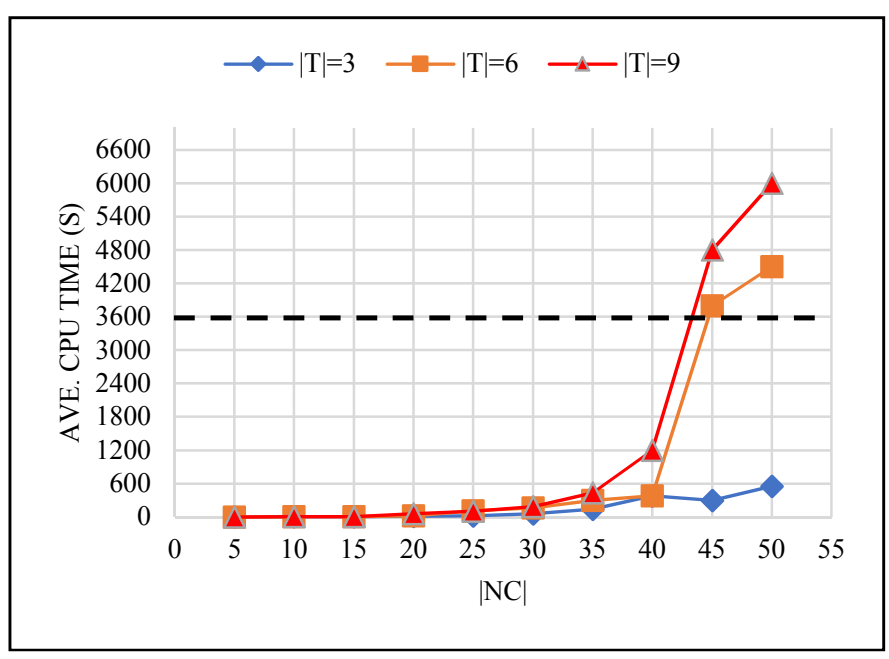

\section{CONCLUSION \& PERSPECTIVES}

In this paper, an extension of the integrated productioninventory-routing problem was studied by considering the case of collecting and remanufacturing end-of-life products within a closed-loop supply chain. We presented a MILP formulation for the considered problem. The proposed model aims to jointly optimize the capacited dynamic lot-sizing with remanufacturing problem and the vehicle routing problem with simultaneous pickup and delivery. This joint optimization in the context of reverse logistics networks represents both an economic interest, as long as we minimize the total cost of the considered operations, and a challenging issue since each of the considered problems is NP-hard. The numerical results show the need to develop approximate resolution methods for resolving large instances. This fact is due to the considerable number of variables induced by the proposed model. Moreover, the next step would be to further develop the proposed model and expand it to cover more realistic real-life situations by considering the multi-item lot-sizing with remanufacturing problem, at production level, and considering a heterogenous fleet of vehicles with divisible deliveries and pickups at distribution level.

\section{REFERENCES}

[1] Ruokokoski, M., Solyali, O. G. U. Z., Cordeau, J. F., Jans, R., \& Süral, H. (2010). Efficient formulations and a branch-and-cut algorithm for a production-routing problem. GERAD Technical Report G-2010-66. 
[2] Moons, S., Ramaekers, K., Caris, A., \& Arda, Y. (2016). Integrating production scheduling and vehicle routing decisions at the operational decision level: a review and discussion. Computers \& Industrial Engineering.

[3] Díaz-Madroñero, M., Peidro, D., \& Mula, J. (2015). A review of tactical optimization models for integrated production and transport routing planning decisions. Computers \& Industrial Engineering, 88, 518-535.

[4] Adulyasak, Y., Cordeau, J. F., \& Jans, R. (2013). Formulations and branch-and-cut algorithms for multivehicle production and inventory routing problems. INFORMS Journal on Computing, 26(1), 103-120.

[5] Archetti, C., Bertazzi, L., Paletta, G., \& Speranza, M. G. (2011). Analysis of the maximum level policy in a production-distribution system. Computers \& Operations Research, 38(12), 1731-1746.

[6] Adulyasak, Y., Cordeau, J. F., \& Jans, R. (2012). Optimization-based adaptive large neighborhood search for the production routing problem. Transportation Science, 48(1), 20-45.

[7] Bard, J. F., \& Nananukul, N. (2009). Heuristics for a multiperiod inventory routing problem with production decisions. Computers \& Industrial Engineering, 57(3), 713-723.

[8] Bard, J. F., \& Nananukul, N. (2010). A branch-and-price algorithm for an integrated production and inventory routing problem. Computers \& Operations Research, 37(12), 2202-2217.

[9] Adulyasak, Y., Cordeau, J. F., \& Jans, R. (2015). The production routing problem: A review of formulations and solution algorithms. Computers \& Operations Research, 55, 141-152.

[10] Coelho, L. C., Cordeau, J. F., \& Laporte, G. (2013). Thirty years of inventory routing. Transportation Science, 48(1), 1-19.

[11] Bard, J. F., \& Nananukul, N. (2009). The integrated productioninventory-distribution-routing problem. Journal of Scheduling, 12(3), 257-280.

[12] DeCroix, G. A. (2006). Optimal policy for a multiechelon inventory system with remanufacturing. Operations Research, 54(3), 532-543.

[13] Wagner, H. M., \& Whitin, T. M. (1958). Dynamic version of the economic lot size model. Management science, 5(1), 89-96.

[14] Aloulou, M. A., Dolgui, A., \& Kovalyov, M. Y. (2014). A bibliography of non-deterministic lot-sizing models. International Journal of Production Research, 52(8), 2293-2310.

[15] Bazan, E., Jaber, M. Y., \& Zanoni, S. (2016). A review of mathematical inventory models for reverse logistics and the future of its modeling: An environmental perspective. Applied Mathematical Modelling, 40(5), 4151-4178.

[16] Masmoudi, O., Yalaoui, A., Ouazene, Y., \& Chehade, H. (2016). Multiitem capacitated lot-sizing problem in a flow-shop system with energy consideration. IFAC-PapersOnLine, 49(12), 301-306.

[17] Zhang, Z. H., Jiang, H., \& Pan, X. (2012). A Lagrangian relaxation based approach for the capacitated lot sizing problem in closed-loop supply chain. International Journal of Production Economics, 140(1), 249-255.

[18] Piñeyro, P., \& Viera, O. (2015). The economic lot-sizing problem with remanufacturing: analysis and an improved algorithm. Journal of Remanufacturing, 5(1), 12.
[19] Schulz, T. (2011). A new Silver-Meal based heuristic for the single-item dynamic lot sizing problem with returns and remanufacturing. International Journal of Production Research, 49(9), 2519-2533.

[20] Sifaleras, A., Konstantaras, I., \& Mladenović, N. (2015). Variable neighborhood search for the economic lot sizing problem with product returns and recovery. International Journal of Production Economics, 160, 133-143.

[21] Cunha, J. O., \& Melo, R. A. (2016). A computational comparison of formulations for the economic lot-sizing with remanufacturing. Computers \& Industrial Engineering, 92, 72-81.

[22] Retel Helmrich, M. J., Jans, R., van den Heuvel, W., \& Wagelmans, A. P. (2014). Economic lot-sizing with remanufacturing: complexity and efficient formulations. IIE Transactions, 46(1), 67-86.

[23] Karaoglan, I., Altiparmak, F., Kara, I., \& Dengiz, B. (2009). Vehicle Routing Problem with Simultaneous Pickup and Delivery: Mixed Integer Programming Formulations and Comparative Analyses. Research Paper. Research Paper.

[24] Chen, J. F., \& Wu, T. H. (2006). Vehicle routing problem with simultaneous deliveries and pickups. Journal of the Operational Research Society, 57(5), 579-587.

[25] Min, H. (1989). The multiple vehicle routing problem with simultaneous delivery and pick-up points. Transportation Research Part A: General, 23(5), 377-386

[26] Polat, O., Kalayci, C. B., Kulak, O., \& Günther, H. O. (2015). A perturbation based variable neighborhood search heuristic for solving the vehicle routing problem with simultaneous pickup and delivery with time limit. European Journal of Operational Research, 242(2), 369-382.

[27] Tchoupo, M. N., Yalaoui, A., Amodeo, L., Yalaoui, F., \& Lutz, F. (2017, September). Ant Colony Optimization Algorithm for Pickup and Delivery Problem with Time Windows. In International Conference on Optimization and Decision Science (pp. 181-191). Springer, Cham.

[28] Kalayci, C. B., \& Kaya, C. (2016). An ant colony system empowered variable neighborhood search algorithm for the vehicle routing problem with simultaneous pickup and delivery. Expert Systems with Applications, 66, 163-175.

[29] Euchi, J., \& Euchi, J. (2017). Genetic scatter search algorithm to solve the one-commodity pickup and delivery vehicle routing problem. Journal of Modelling in Management, 12(1), 2-18.

[30] Dell'Amico, M., Righini, G., \& Salani, M. (2006). A branch-and-price approach to the vehicle routing problem with simultaneous distribution and collection. Transportation Science, 40(2), 235-247.

[31] Berbeglia, G., Cordeau, J. F., Gribkovskaia, I., \& Laporte, G. (2007). Static pickup and delivery problems: a classification scheme and survey. Top, 15(1), 1-31

[32] Parragh, S. N., Doerner, K. F., \& Hartl, R. F. (2008). A survey on pickup and delivery problems. Management Review Quarterly, 58(2), 81-117.

[33] Senoussi, A., Mouss, N. K., Penz, B., Brahimi, N., \& Dauzère-Pérès, S. (2016). Modeling and solving a one-supplier multi-vehicle productioninventory-distribution problem with clustered retailers. The International Journal of Advanced Manufacturing Technology, 85(5-8), 971-989. (33) 